\title{
The National Early Warning Score adapted to pregnancy in case of suspicion of COVID-19 infection: evaluation in a retrospective study.
}

Louise Ghesquiere $^{1}$, marc lambert ${ }^{2}$, cecile yelnik ${ }^{2}$, Mercé Jourdain ${ }^{3}$, Fanny Vuotto ${ }^{3}$, Damien Subtil ${ }^{4}$, Karine Faure ${ }^{3}$, and Charles Garabedian ${ }^{4}$

${ }^{1}$ CHRU Lille, hopital Jeanne-De-Flandre

${ }^{2}$ Affiliation not available

${ }^{3}$ CHRU de Lille

${ }^{4}$ Jeanne De Flandre

May 18, 2020

\begin{abstract}
Objective - Determine what is the best initial clinical score to evaluate and propose adequate management to pregnant women with suspicion of COVID-19 infection. Design - setting - population: Retrospective study in one center (Lille, France) from 15 March 2020 to 15 April 2020. Were included all pregnant consulting in our emergency center for a suspicion of COVID19 infection. Methods - main outcome measures: Women had a clinical, radiologic and biologic first evaluation to adapt management at home or in hospitalization. The National Early Warning Score (NEWS) and the NEWS-PREG, which is an adaptation including trimester of pregnancy, were calculated in posteriori for each patient. Sensitivity, specificity, predictive positive and negative value of these scores to propose adequate management were calculated. Results: 63 women were included. Seventeen were hospitalized $(27 \%)$ among 4 in intensive care $(6,5 \%)$. Sensitivity, specificity, predictive positive value and predictive negative value to predict hospitalization of the NEWS were respectively $52.9 \%, 100 \%, 100 \%$ and $85.2 \%$. There were respectively $82.4 \%, 93.5 \%, 82.4 \%$ and $93.4 \%$ for the NEWS-PREG. Areas under the curve to predict hospitalization of the two scores were 0.77 for the NEWS and 0.88 for the NEWS-PREG. No woman was readmitted or had to be transferred from conventionel hospitalization to intensive care within 48 hours of her initial assessment and orientation. Conclusion: The NEWS-PREG is an interesting initial clinical score which can be used in case of suspicion of COVID-19 infection to propose adequate management. It will be interesting to evaluate in a prospective study.
\end{abstract}

\section{Main text:}

\section{Introduction}

The current pneumonia outbreak of coronavirus disease 2019 (COVID-19), caused by the severe acute respiratory syndrome coronavirus 2 (SARS-CoV-2), has been declared a pandemic by the World Health Organization (WHO) on March 11, 20201. Pregnant women and their fetuses represent a high-risk population during infectious disease outbreaks ${ }^{2-5}$. In 215 pregnant women admitted for delivery in New York, 33 patients were SARS-CoV-2 positive $(15,4 \%)$ with 4 symptomatic $(1,9 \%)$ and 29 asymptomatic $(13,5 \%)^{6}$. Pregnancy complications included delivery by cesarean section $(84 \%)$, preterm labor $<37$ weeks $(24.3 \%)$, premature rupture of membranes $(20.7 \%)$, preeclampsia (16.2\%), fetal growth restriction (11.7\%). Di Mascio et al. described a rate of perinatal death at $7-11 \%$ and $57.2 \%$ of new born were admitted to the neonatal intensive care unit. Vertical transmission is unlikely and still discussed ${ }^{7}$. Serious morbidities were reported in $3 \%$ of pregnant women with COVID-19 as they required ICU care with mechanical ventilation ${ }^{8}$. 
Different guidelines have been published by international expert consensus or national society or experts ${ }^{2,9-12}$. However, none proposed a score for the initial clinical examination which could help the clinician in their algorithm of decision. The National Early Warning Score (NEWS) determines the degree of illness of a patient using six physiological findings and one observation ${ }^{13}$. It has been tested in many situations and has the ability to discriminate patients at risk of morbidity or mortality ${ }^{13-15}$. This score or its second version is also used in studies evaluating treatment in severe COVID-19 situations ${ }^{16}$. In the context of the actual pandemic, Liao et al. proposed a modified version of the NEWS with age [?] 65 years added for early recognition of patients with severe COVID-19 infection and admission decisions according to the severity classification $^{17}$.

In the same way, we proposed a modified one including the trimester of pregnancy, the NEWS-PREG, with the objective to help the decision of the clinician during the initial evaluation of a pregnant woman with a suspicion of COVID-19 infection. Therefore, the objective of our study was to determine if the NEWS and the NEWS-PREG were able to evaluate and propose adequate management to pregnant patients with suspicion of COVID-19 infection.

\section{Methods}

This retrospective cohort study was conducted in one center (Lille, France) from 15 March 2020 to 15 April 2020. Were included all pregnant consulting in our emergency center for a suspicion of COVID-19 infection. During this consultation, women had a clinical examination and then radiologic (chest X-ray or CT scan) and laboratory test. The clinical evaluation included an interrogation on comorbidities and COVID-19 symptoms (cough, fever, dyspnea, rhinitis, chest tightness, headache, myalgia, anosmia-agueusia, gastrointestinal symptoms) as well as their date of appearance. The radiologic evaluation researched sign of COVID-19 described in literature (pneumonia, ground glass opacities, consolidations, multifocal lesions... $)^{18}$. Laboratory test results were compiled, including standard blood counts (absolute white blood cells, neutrophils and lymphocytes) and C-reactive protein ${ }^{19}$. All women had a quantitative Reverse transcriptase-polymerase chain reaction (qRT-PCR) to confirm COVID-19 infection via nasopharyngeal swab test. The qRT-PCR result was obtained $24 \mathrm{~h}-48 \mathrm{~h}$ after the swab test. Depend clinical symptoms, chest-X ray or pulmonary CT scan and routine blood test, women returned at home or were admitted to an isolated suite or intensive care in our hospital.

For each patient, we retrospectively calculated the NEWS and the NEWS-PREG (Table 1). The NEWS is a score based on 8 parameters: age (years), respiration rate $(/ \mathrm{mn})$, oxygen saturations, need for supplemental oxygen, systolic blood pressure $(\mathrm{mmHg})$, heart rate $(\mathrm{bpm})$, consciousness and temperature $\left({ }^{\circ} \mathrm{C}\right)$. Each parameter is set between 0 and 3. In complement with the NEWS, due to the particular situation of the pregnancy, we proposed the NEWS-PREG (Table 1). We have replaced the age as proposed by Liao et al., by the trimester of pregnancy. The second trimester is set 1 point and the third trimester is set 2 points. We made this choice to adapt it in function of pregnancy trimester regarding the literature on pandemic 2009 Influenza A(H1N1) and influenza that found a higher risk of mortality in the second and third trimester ${ }^{20,21}$. Thus, particular attention should be given to pregnant women in the second and in the third trimester. After calculation of the score, inpatient management is proposed in case of a score greater than or equal to $5^{17}$. The evolution of the patient 2 days after her first consultation was noted to determine if the patient was well classed during her first evaluation. The principal endpoint was to determine what was the best evaluation initial between NEWS and NEWS-PREG. The secondary objective was to compare characteristics (clinic, biologic and radiologic) of patients managed at home with patients hospitalized.

\section{Statistical analysis}

Categorical variables are described as numbers and percentage. Continuous variables are reported as median ( $1^{\text {st }}$ quartile; $3^{\text {rd }}$ quartile). A nonparametric Mann-Whitney U test was used for intergroup comparisons of continuous variables. Categorical variables were analyzed with a Khi2 test or Fisher test. A p value $<0$ .05 was considered significant. ROC analysis was performed to evaluate the ability of NEWS and NEWSPREG to predict the patient hospitalization. An area under the ROC $>0.80$ was considered significant. 
We determined sensitivity, specificity, positive predictive value and negative predictive value of NEWS and NEWS-PREG to predict hospitalization. The tests were performed using the IBM SPSS statistics 20.0.

\section{Results:}

Sixty-three women were included. Table 2 reports the characteristics of the population. The median age of patients was $31(26.8 ; 33.8)$ years. Gestational age at first consultation was $24(18 ; 30.1)$ weeks of gestation with 14 patients in first trimester $(22.2 \%), 27$ in second trimester $(42.9 \%)$ and 22 in third trimester (34.9\%). In median, women consulted 6 days after first COVID-19 symptoms ( $3 ; 9$ days). Principal symptom was cough (76.2\%). The others symptoms were headache $(39,7 \%)$, fever $(34,9 \%)$, dyspnea $(36.5 \%)$, rhinitis $(33,3 \%)$, myalgia (27\%), chest tightness $(22,2 \%)$, anosmia-ageusia (20,6\%). In these 63 women, 14 had a PCR COVID19 positive $(22.2 \%)$. 17 were hospitalized $(27 \%)$ among 4 in intensive care $(6,5 \%)$. Clinical symptoms more frequent at women confirmed COVID-19 positive were cough (85.7\%), fever (50\%), headache (57.1\%), myalgia (42.9\%) and dyspnea (35.7\%). $35.7 \%$ were hospitalized (5/14).

The median of NEWS was 1 (0.5-3) and of the NEWS-PREG was 3 (1-5). For all the population, sensitivity, specificity, predictive positive value and predictive negative value to predict hospitalization of the NEWS were respectively $52.9 \%, 100 \%, 100 \%$ and $85.2 \%$. There were respectively $82.4 \%, 93.5 \%, 82.4 \%$ and $93.4 \%$ for the NEWS-PREG. Areas under the curve of the two scores to predict hospitalization were 0.77 for the NEWS and 0.88 for the NEWS-PREG (Figure 1).

No woman was readmitted or had to be transferred from conventionel hospitalization to intensive care within 48 hours of her initial assessment and orientation.

In women with NEWS-PREG $<5$, three were hospitalized. For these 3 women, radiologic and biologic exams were abnormal with interstitial syndrome and inflammatory syndrome. In the contrary, 3 women with NEWS-PREG $=5$ were not hospitalized. For these patients, the chest X-ray was normal and the outcome was good. All women with NEWS-PREG $>6(\mathrm{n}=10)$ had chest X-ray abnormalities and 90\% $(9 / 10)$ had an inflammatory biologic syndrome.

Table 3 shows the comparison between patients managed at home and hospitalized. There were no significant difference in gestational age between the two group with a tendency of lower gestational age in women managed at home (22.6 WG (14.2-30) vs 27.5 WG (21.8-32.7), $\mathrm{p}=0.065)$. More comorbidity were observed in the hospitalization group with $35.3 \%$ of obesity, $23.5 \%$ of pulmonary disease and $17.6 \%$ of gestational diabetic. There was no significant difference between two groups concerning numbers of positive qRT-PCR to confirm COVID-19 infection. Concerning clinical symptoms, dyspnea was significantly more frequent in the hospitalization group $(56.3 \%$ vs $28.3 \%, \mathrm{p}<0.05)$. Headache and diarrhea were significantly more frequent in the no hospitalization group (respectively $47.8 \%$ vs $12.5 \%$ and $21.7 \%$ vs $0 \%$ ). Clinical evaluation founded NEWS and NEWS-PREG significantly higher in hospitalization group, respectively 5 (3-6.5) and 6 (5-8), than in no hospitalization group, $1(0-1.25)$ and $2(1-3), \mathrm{p}<0.001$. In hospitalization group, there were more abnormal chest X-Ray or CT scan $(82.4 \%$ vs $5.1 \%, \mathrm{p}<0.05)$ and more inflammatory syndrome $(76.5 \%$ vs $12.5 \%, \mathrm{p}<0.05)$.

\section{Discussion:}

\section{Main findings:}

Due to its potential gravity, it is important in COVID-19 disease to early recognize and propose adequate management especially for pregnant women. A physiological parameter-based warning score adapted for pregnant women, the NEWS-PREG, was evaluated in our center to facilitate early recognition of patients with severe infection and admission decisions according to the severity classification. The sensibility, specificity, predictive positive and negative value were higher than $80 \%$ (respectively $82.4 \%, 93.5 \%, 82.4 \%, 93.4 \%$ ) and none women were changed orientation during the $48 \mathrm{~h}$ after her initial evaluation. This score seemed more adapted to pregnant women than the NEWS with a better sensibility and a better AUC. Thus, this score could help clinicians in the initial clinical evaluation of pregnant women with COVID 19 suspicion and could be a complement to previous algorithms and recommendations published ${ }^{9,22,23}$. Its association 
with comorbidity and radiologic exam results in the initial evaluation would further improve management of pregnant women.

Characteristics of patients in our population were similar of previous studies ${ }^{24-26}$ : principal symptoms were cough $(76.2 \%)$, fever $(34.9 \%)$, dyspnea (36.5\%) and headache $(39.7 \%)$. In COVID-19 positive patients confirmed (RT-PCR positive), there were more fever $(50 \%)$, myalgia $(42.9 \%)$ and headache $(57.1 \%)$. In review of COVID-19, in pregnant women with COVID-19, the most common symptoms were fever (54\%), cough $(35 \%)$, myalgia (17\%), dyspnea (12\%) and diarrhea (4\%). Clinical symptom that seemed to be more predictive of severity and hospitalization was dyspnea with a significant difference between two groups. Symptoms that seemed to be more predictive of no severe disease were diarrhea and headache.

Women hospitalized had initial NEWS and NEWS-PREG higher than women managed at home and had more severe disease. These confirm efficiency in clinical score for initial women evaluation and orientation. In addition to this clinical evaluation, recommendation proposed the search of a radiological evaluation $12,18,22,23$. Chest X-Ray or CT scan shown more abnormalities in hospitalization group ( $82.4 \%$ versus $5.1 \%)$. It was observed, as previously described, ground-glass opacities or mixed ground-glass opacities, consolidations, peripheral distribution, bilateral involvement, be lower lung predominant and multifocal ${ }^{18,22,27}$. These typical lesions can be helpful in early screening of highly suspected cases and in evaluation of the severity and extent of the disease. Indeed, Chest CT scanning has high sensitivity for diagnosis of COVID-19 and in a pregnant woman with suspected COVID-19 infection, a chest CT scan may be considered as a primary tool for the detection of COVID-19 in epidemic areas ${ }^{23}$.

Strengths and limitations:

None score has actually been proposed for initial clinical evaluation of pregnant women with suspicion of COVID-19 infection. This score is adapted from the National Early Warning Score (NEWS), a score known to discriminate the initial severity of patients used early warning scoring systems based on the derangement of patients' vital signs variables (e.g., pulse rate, breathing rate, blood pressure) $)^{13,15,28,29}$. The sum of the allocated points is used to direct care involve more experienced staff or call a rapid response team. Its second version is also used in studies evaluating treatments for COVID 19 infection ${ }^{16}$. We made the choice to adapt it in function of pregnancy trimester regarding the literature on pandemic 2009 Influenza A (H1N1) and influenza. Indeed, Siston et al. reported the outcome of 788 pregnant women in the United States with 2009 influenza $\mathrm{A}(\mathrm{H} 1 \mathrm{~N} 1){ }^{20}$. Among those, 30 died, 4 during the first trimester $(7.1 \%), 15$ in the second $(26.8 \%)$ and 36 in the third $(64.3 \%)$. This higher risk of mortality is also observed in the influenza ${ }^{21}$. Thus, particular attention should be given to pregnant women in the second and in the third trimester.

Tested in our population, this score shown encouraging results with high specificity and predictive negative value. However, six patients were managed differently as we proposed with the NEWS-PREG. Three patients had a NEWS-PREG less than 5 but were hospitalized. For these 3 cases, the chest X-ray as well as the blood test were abnormal explaining their hospitalization. It is known that in some forms of COVID-19, the clinic evaluation can be reassuring, but that the chest X-ray or CT scan can be worrying and requires inpatient monitoring for the risk of rapid clinical worsening ${ }^{27,30}$. Three cases had a NEWS-PREG [?] 5 and were not hospitalized. For these three cases, chest X-ray and blood test were reassuring with no abnormality and evolution was good with home management.

Our study has limitations. The sample size was small in the NEWS-PREG [?]5 group. Majority of pregnant women who consulted for a suspicion of COVID- 19 were in mild or asymptomatic degree. Only 14 women had a RT-PCR positive probably due to the lack of sensibility of RT-PCR.

\section{Conclusion}

NEWS-PREG could be used to evaluate and propose management of pregnant women with suspicion of COVID-19. It could help the clinician for initial evaluation as also radiological and biological examination. Moreover, this score is based on physiological parameters easy to obtain in emergency centers and its interpretation is also simple. It will be interesting to evaluate it prospectively and in a larger cohort. 


\section{Disclosure of Interests:}

All authors report no conflict of interest.

\section{Contribution to Authorship:}

All of the authors participated. L. Ghesquiere, M. Lambert, C. Yelnik, M. Jourdain, F. Vuotto, D. Subtil, K. Faure, C. Garabedian supervised and corrected this article. C. Garabedian is the principal investigator of the study. L. Ghesquiere, M. Lambert, F. Vuotto participated to include patients. L. Ghesquiere did the statistic analysis. L. Ghesquiere written article. C. Garabedian, C. Yelnik, M. Lambert reread the article.

\section{Details of Ethics Approval:}

The study was approved by the local committee of the national ethical commission (CNIL NdegDEC20-114 on $04 / 17 / 2020)$.

Funding: No funding

\section{References}

1. WHO Director-General's opening remarks at the media briefing on COVID-19 - 11 March 2020. Available at https://www.who.int/dg/speeches/detail/who-directorgeneral-s-opening-remarks-at-the-mediabriefing-on-covid-19-11-march-2020).

2. Dashraath P, Jing Lin Jeslyn W, Mei Xian Karen L, Li Min L, Sarah L, Biswas A, et al. Coronavirus Disease 2019 (COVID-19) Pandemic and Pregnancy. Am J Obstet Gynecol. 2020 Mar 23. S00029378(20)30343-4.

3. Dong L, Tian J, He S, Zhu C, Wang J, Liu C, et al. Possible Vertical Transmission of SARS-CoV-2 From an Infected Mother to Her Newborn. JAMA. 2020 Mar 26. doi: 10.1001/jama.2020.4621

4. Chen H, Guo J, Wang C, Luo F, Yu X, Zhang W, et al. Clinical characteristics and intrauterine vertical transmission potential of COVID-19 infection in nine pregnant women: a retrospective review of medical records. The Lancet. 2020 Feb;S0140673620303603.

5. Schwartz DA. An Analysis of 38 Pregnant Women with COVID-19, Their Newborn Infants, and MaternalFetal Transmission of SARS-CoV-2: Maternal Coronavirus Infections and Pregnancy Outcomes. Arch Pathol Lab Med. 2020 Mar 17;arpa.2020-0901-SA.

6. Sutton. Universal Screening for SARS-CoV-2 in Women Admitted for Delivery. Sutton D, Fuchs K, D'Alton M, Goffman D. N Engl J Med. 2020 Apr 13. doi: 10.1056/NEJMc2009316.

7. Di Mascio D, Khalil A, Saccone G, Rizzo G, Buca D, Liberati M, et al. Outcome of Coronavirus spectrum infections (SARS, MERS, COVID 1 -19) during pregnancy: a systematic review and meta-analysis. Am J Obstet Gynecol MFM. 2020 Mar 25;100107.

8. Zaigham M, Andersson O. Maternal and perinatal outcomes with COVID-19: A systematic review of 108 pregnancies. Acta Obstet Gynecol Scand. 2020 Apr 7;

9. Favre G, Pomar L, Qi X, Nielsen-Saines K, Musso D, Baud D. Guidelines for pregnant women with suspected SARS-CoV-2 infection. Lancet Infect Dis. 2020 Mar;S1473309920301572.

10. Liang H, Acharya G. Novel corona virus disease (COVID-19) in pregnancy: What clinical recommendations to follow? Acta Obstet Gynecol Scand. 2020;99(4):439-42.

11. Chen D, Yang H, Cao Y, Cheng W, Duan T, Fan C, et al. Expert consensus for managing pregnant women and neonates born to mothers with suspected or confirmed novel coronavirus (COVID-19) infection. Int J Gynecol Obstet. 2020 May;149(2):130-136. 
12. Peyronnet V, Sibiude J, Deruelle P, Huissoud C, Lescure X, Lucet J-C, et al. [SARS-CoV-2 infection during pregnancy. Information and proposal of management care. CNGOF]. Gynecol Obstet Fertil Senol. 2020 Mar 19

13. Smith GB, Prytherch DR, Meredith P, Schmidt PE, Featherstone PI. The ability of the National Early Warning Score (NEWS) to discriminate patients at risk of early cardiac arrest, unanticipated intensive care unit admission, and death. Resuscitation. 2013 Apr; 84(4):465-70.

14. Kovacs C, Jarvis SW, Prytherch DR, Meredith P, Schmidt PE, Briggs JS, et al. Comparison of the National Early Warning Score in non-elective medical and surgical patients. Br J Surg. 2016 Sep;103(10):138593.

15. Jarvis S, Kovacs C, Briggs J, Meredith P, Schmidt PE, Featherstone PI, et al. Aggregate National Early Warning Score (NEWS) values are more important than high scores for a single vital signs parameter for discriminating the risk of adverse outcomes. Resuscitation. 2015 Feb;87:75-80.

16. Cao B, Wang Y, Wen D, Liu W, Wang J, Fan G, et al. A Trial of Lopinavir-Ritonavir in Adults Hospitalized with Severe Covid-19. N Engl J Med. 2020 Mar 18;NEJMoa2001282.

17. Liao X, Wang B, Kang Y. Novel coronavirus infection during the 2019-2020 epidemic: preparing intensive care units - the experience in Sichuan Province, China. Intensive Care Med. 2020 Feb;46(2):357-60.

18. Wu X, Sun R, Chen J, Xie Y, Zhang S, Wang X. Radiological findings and clinical characteristics of pregnant women with COVID-19 pneumonia. Int J Gynaecol Obstet Off Organ Int Fed Gynaecol Obstet. 2020 Apr 8;

19. Wu C, Yang W, Wu X, Zhang T, Zhao Y, Ren W, et al. Clinical Manifestation and Laboratory Characteristics of SARS-CoV-2 Infection in Pregnant Women. Virol Sin. 2020 Apr 20;

20. Siston AM, Rasmussen SA, Honein MA, Fry AM, Seib K, Callaghan WM, et al. Pandemic 2009 Influenza A(H1N1) Virus Illness Among Pregnant Women in the United States. JAMA. 2010 Apr 21;303(15):1517-25.

21. Neuzil KM, Reed GW, Mitchel EF, Simonsen L, Griffin MR. Impact of Influenza on Acute Cardiopulmonary Hospitalizations in Pregnant Women. Am J Epidemiol. 1998 Dec 1;148(11):1094-102.

22. Ashokka B, Loh M-H, Tan CH, Su LL, Young BE, Lye DC, et al. Care of the Pregnant Woman with COVID-19 in Labor and Delivery: Anesthesia, Emergency cesarean delivery, Differential diagnosis in the acutely ill parturient, Care of the newborn, and Protection of the healthcare personnel. Am J Obstet Gynecol. 2020 Apr 10;

23. Poon LC, Yang H, Kapur A, Melamed N, Dao B, Divakar H, et al. Global interim guidance on coronavirus disease 2019 (COVID-19) during pregnancy and puerperium from FIGO and allied partners: Information for healthcare professionals. Int J Gynecol Obstet [Internet]. [cited 2020 Apr 27]. Available from: http://obgyn.onlinelibrary.wiley.com/doi/abs/10.1002/ijgo.13156

24. Yang H, Sun G, Tang F, Peng M, Gao Y, Peng J, et al. Clinical Features and Outcomes of Pregnant Women Suspected of Coronavirus Disease 2019. J Infect. 2020 Apr 12;

25. Della Gatta AN, Rizzo R, Pilu G, Simonazzi G. COVID19 during pregnancy: a systematic review of reported cases. Am J Obstet Gynecol. 2020 Apr 17;

26. Chen L, Li Q, Zheng D, Jiang H, Wei Y, Zou L, et al. Clinical Characteristics of Pregnant Women with Covid-19 in Wuhan, China. N Engl J Med. 2020 Apr 17;

27. Li K, Fang Y, Li W, Pan C, Qin P, Zhong Y, et al. CT image visual quantitative evaluation and clinical classification of coronavirus disease (COVID-19). Eur Radiol. 2020 Mar 25;

28. Scott L. Association between National Early Warning Scores in primary care and clinical outcomes: an observational study in UK primary and secondary care. Scott LJ, Redmond NM, Tavare A, Little H, 
Srivastava S, Pullyblank A. Br J Gen Pract. 2020 Apr 6. pii: bjgp20X709337. doi: 10.3399/bjgp20X709337. [Epub ahead of print].

29. Royal College of Physicians. National Early Warning Score (NEWS): standardising the assessment of acute-illness severity in the NHS. London: RCP, 2012.

30. Liu H, Liu F, Li J, Zhang T, Wang D, Lan W. Clinical and CT imaging features of the COVID-19 pneumonia: Focus on pregnant women and children. J Infect. 2020;80(5):e7-13.

Table 1: NEWS-PREG

\begin{tabular}{|c|c|c|c|c|c|c|c|}
\hline \multicolumn{2}{|c|}{ PARAMETERS } & \multirow[t]{2}{*}{2} & \multirow[t]{2}{*}{1} & \multirow[t]{2}{*}{0} & \multirow{2}{*}{$\begin{array}{ll}1 \\
15-27\end{array}$} & \multirow{2}{*}{$\begin{array}{l}\mathbf{2} \\
28-42\end{array}$} & \multirow[t]{2}{*}{3} \\
\hline $\begin{array}{l}\text { Weeks of } \\
\text { gestation }\end{array}$ & & & & & & & \\
\hline $\begin{array}{l}\text { Respiration } \\
\text { rate } \\
(/ \mathrm{mn})\end{array}$ & $? 8$ & & $9-11$ & $12-20$ & & $21-24$ & $? 25$ \\
\hline $\begin{array}{l}\text { Oxygen } \\
\text { satura- } \\
\text { tions }\end{array}$ & $? 91$ & $92-93$ & 94-95 & ? 96 & & & \\
\hline $\begin{array}{l}\text { Any } \\
\text { supple- } \\
\text { mental } \\
\text { oxygen }\end{array}$ & & Yes & & No & & & \\
\hline $\begin{array}{l}\text { Systolic } \\
\text { BP } \\
(\mathrm{mmHg})\end{array}$ & $? 90$ & $91-100$ & $101-110$ & 111-219 & & & $? 220$ \\
\hline $\begin{array}{l}\text { Heart } \\
\text { rate } \\
(\text { bpm })\end{array}$ & $? 40$ & & $41-50$ & $51-90$ & $91-110$ & $111-130$ & ? 131 \\
\hline Consciousness & & & & Alert & & & $\begin{array}{l}\text { Drowsiness } \\
\text { Lethargy } \\
\text { Coma } \\
\text { Confusion }\end{array}$ \\
\hline $\begin{array}{l}\text { Temperature } \\
\left({ }^{\circ} \mathrm{C}\right)\end{array}$ & $? 35.0$ & & $35.1-36.0$ & $36.1-38.0$ & $38.1-39.0$ & ? 39.1 & \\
\hline
\end{tabular}

BP: Blood Pressure

Table 2 - Demographic and Clinical Characteristics of Pregnant Women

\begin{tabular}{|c|c|c|}
\hline & All patients $(\mathrm{N}=63)$ & $\mathrm{COVID}+(\mathrm{N}=14)$ \\
\hline \multicolumn{3}{|l|}{ General Characteristics } \\
\hline Age (years) & $31(26.8 ; 33.8)$ & $29.3(25.9 ; 31.2)$ \\
\hline Gestational age (WG) & $24(18 ; 30.1)$ & $24.6(18.3 ; 29.8)$ \\
\hline Comorbidity $\mathrm{BMI}>30$ & 744 & 313 \\
\hline \multicolumn{3}{|l|}{$\begin{array}{l}\text { Pulmonary disease Gestational } \\
\text { Diabetic }\end{array}$} \\
\hline Signs and symptoms & & \\
\hline $\begin{array}{l}\text { Time (days) between the } \\
\text { beginning of symptoms and first } \\
\text { consultation }\end{array}$ & $6(3 ; 9)$ & $8(4 ; 9)$ \\
\hline
\end{tabular}




\begin{tabular}{lll}
\hline & All patients (N=63) & COVID+ (N=14) \\
\hline Cough & $48(76.2 \%)$ & $12(85.7 \%)$ \\
Fever & $22(34.9 \%)$ & $7(50 \%)$ \\
Dyspnea & $23(36.5 \%)$ & $5(35.7 \%)$ \\
Rhinitis & $21(33.3 \%)$ & $4(28.6 \%)$ \\
Chest tightness & $14(22.2 \%)$ & $2(14.3 \%)$ \\
Headache & $25(39.7 \%)$ & $8(57.1 \%)$ \\
Myalgia & $17(27 \%)$ & $6(42.9 \%)$ \\
Anosmia-agueusia & $13(20.6 \%)$ & $4(28.6 \%)$ \\
Diarrhea & $10(15.9 \%)$ & $2(14.3 \%)$ \\
Inflammatory syndrome at the & $14(22.2 \%)$ & $5(62.5 \%)$ \\
blood test & $16(25.4 \%)$ & $7(58.3 \%)$ \\
Abnormal Chest X-Ray or CT & $17(27 \%)$ & $5(35.7 \%)$ \\
Scan & $13(20.6 \%)$ & $4(28.6 \%)$ \\
Hospitalization & $4(6.3 \%)$ & $1(7.1 \%)$ \\
Conventional & & \\
Intensive care & &
\end{tabular}

$B M I=$ Body Mass Index; $W G=$ weeks of gestation. Data are on median ( $1^{\text {st }}$ quartile; $3^{\text {rd }}$ quartile) or $N$ (\%)

Table 3 - Characteristics of the population according to hospitalization or no.

\begin{tabular}{|c|c|c|c|}
\hline & $\begin{array}{l}\text { No hospitalization } \\
(\mathrm{n}=46)\end{array}$ & Hospitalization $(\mathrm{n}=17)$ & $\mathrm{p}$ \\
\hline \multicolumn{4}{|l|}{ General Characteristics } \\
\hline Age (years) & $31.3(28.1 ; 34.1)$ & $29.3(24.7 ; 33.1)$ & 0.253 \\
\hline Gestational age (WG) & $22.6(14.2 ; 30.0)$ & $27.5(21.8 ; 32.7)$ & 0.065 \\
\hline Comorbidity BMI $>30$ & $1(2.1 \%) 0(0 \%) 1$ & $6(35.3 \%) 4(23.5 \%) 3$ & 0.0010 .0040 .057 \\
\hline $\begin{array}{l}\text { Pulmonary disease } \\
\text { Gestational Diabetes }\end{array}$ & $(2.1 \%)$ & $(17.6 \%)$ & \\
\hline $\begin{array}{l}\text { RT-PCR COVID + } \\
\text { Signs and symptoms }\end{array}$ & $9(19.6 \%)$ & $5(29.4 \%)$ & 0.498 \\
\hline $\begin{array}{l}\text { Time (days) between the } \\
\text { beginning of symptoms } \\
\text { and first consultation }\end{array}$ & $7(3 ; 10)$ & $3.5(1 ; 8.75)$ & 0.042 \\
\hline Cough & $33(71.7 \%)$ & $14 / 16(87.6 \%)$ & 0.314 \\
\hline Fever & $15(32.6 \%)$ & $7 / 15(46.7 \%)$ & 0.325 \\
\hline Dyspnea & $13(28.3 \%)$ & $9 / 16(56.3 \%)$ & 0.044 \\
\hline Rhinitis & $18(39.1 \%)$ & $3 / 16(18.8 \%)$ & 0.138 \\
\hline Chest tightness & $10(21.7 \%)$ & $4 / 13(30.8 \%)$ & 0.485 \\
\hline Headache & $22(47.8 \%)$ & $2 / 16(12.5 \%)$ & 0.012 \\
\hline Myalgia & $12(26.1 \%)$ & $4 / 16(25 \%)$ & 1.000 \\
\hline Anosmia-agueusia & $12(26.1 \%)$ & $1 / 8(12.5 \%)$ & 0.663 \\
\hline Diarrhea & $10(21.7 \%)$ & 0 & 0.052 \\
\hline Score NEWS & $1(0 ; 1.25)$ & $5(3 ; 6.5)$ & $<0.0001$ \\
\hline Score NEWS-PREG & $2(1 ; 3)$ & $6(5 ; 8)$ & $<0.0001$ \\
\hline
\end{tabular}




\begin{tabular}{llll}
\hline & $\begin{array}{l}\text { No hospitalization } \\
(\mathrm{n}=46)\end{array}$ & Hospitalization $(\mathrm{n}=17)$ & $\mathrm{p}$ \\
\hline $\begin{array}{l}\text { Inflammatory } \\
\text { syndrome Blood test }\end{array}$ & $8(17.4 \%) 1 / 8(12.5 \%)$ & $17(100 \%) 13(76.5 \%)$ & $<0.00010 .007$ \\
$\begin{array}{l}\text { Infl. Sd at the blood } \\
\text { test }\end{array}$ & & \\
$\begin{array}{l}\text { Abnormal Chest X-Ray } \\
\text { or CT Scan }\end{array}$ & $2 / 39(5.1 \%)$ & $14(82.4 \%)$ & $<0.0001$ \\
\hline
\end{tabular}

$B M I=$ Body Mass Index; $W G=$ weeks of gestation. Data are on median ( $1^{\text {st }}$ quartile; $3^{\text {rd }}$ quartile) or $N$ (\%). $p<0.05$ is significant.

\section{Figure 1 : ROC curves of prediction of hospitalization}

\section{Hosted file}

image1.emf available at https://authorea.com/users/304509/articles/451982-the-nationalearly-warning-score-adapted-to-pregnancy-in-case-of-suspicion-of-covid-19-infectionevaluation-in-a-retrospective-study

AUC : Area under curve 